\title{
Pharmacological inhibition of macrophage migration inhibitory factor interferes with the proliferation and invasiveness of squamous carcinoma cells
}

\author{
NADĖGE KINDT $^{1 *}$, GUY LAURENT ${ }^{2 *}$, DENIS NONCLERCQ ${ }^{2}$, FABRICE JOURNÉ $^{3}$, GHANEM GHANEM $^{3}$, \\ HUGUES DUVILLIER $^{4}$, HANS-JOACHIM GABIUS ${ }^{6}$, JÉRÔME LECHIEN ${ }^{1}$ and SVEN SAUSSEZ ${ }^{1,5}$
}

\begin{abstract}
Laboratories of ${ }^{1}$ Anatomy and Cellular Biology and ${ }^{2}$ Histology, Faculty of Medicine and Pharmacy, University of Mons, 7000 Mons; Laboratories of ${ }^{3}$ Oncology and Experimental Surgery and ${ }^{4}$ Experimental Hematology, Jules Bordet Institute, ${ }^{5}$ Department of Oto-Rhino-Laryngology, Faculty of Medicine, Université Libre de Bruxelles, 1000 Bruxelles, Belgium; ${ }^{6}$ Institute of Physiological Chemistry, Faculty of Veterinary Medicine, Ludwig Maximillians University, D-80539 Munich, Germany
\end{abstract}

Received November 6, 2012; Accepted December 21, 2012

DOI: $10.3892 /$ ijo.2013.1944

\begin{abstract}
Recent clinical observations and experimental studies of our group indicate that macrophage migration inhibitory factor (MIF) may contribute to tumor progression in head and neck squamous cell carcinomas (HNSCC). The present study was undertaken to examine the effects of the irreversible MIF inhibitor 4-iodo-6-phenylpyrimidine (4-IPP) on proliferation and invasiveness of the squamous carcinoma cell line SCCVII. Cell counting, crystal violet assay and flow cytometry were used to analyze the effects of 4-IPP on SCCVII cell growth. The impact of 4-IPP on cell invasiveness was assessed by Boyden chamber assay. Knockdown of the MIF receptor CD74 was achieved by transduction with lentiviral vectors encoding anti-CD74 shRNAs. As shown by immunofluorescence staining, SCCVII cells express both MIF and CD74. Decreased MIF immunoreactivity as a result of exposure to 4-IPP suggested a covalent modification of the cytokine. 4-IPP inhibited SCCVII cell proliferation and invasiveness. Moreover, the cytostatic effect of 4-IPP was enhanced by CD74 knockdown. The inhibitory effects of 4-IPP on cell proliferation and invasiveness strongly suggest that MIF is involved in proliferative activity and invasive properties of squamous carcinoma cells. In conclusion, MIF inhibition may open possibilities for target-directed treatment of head and neck squamous cell carcinoma.
\end{abstract}

Correspondence to: Professor S. Saussez, Laboratory of Anatomy and Cell Biology, Faculty of Medicine and Pharmacy, University of Mons (UMons), Pentagone 2A, 6 Ave du Champ de Mars, B-7000 Mons, Belgium

E-mail: sven.saussez@umons.ac.be

*Contributed equally

Key words: 4-iodo-6-phenylpyrimidine, head and neck squamous cell carcinoma, cell cycle, cytokine, CD74

\section{Introduction}

Macrophage migration inhibitory factor (MIF), originally named based on its repressive action on the motility of monocytes/macrophages, belongs to the cytokine family of signaling molecules. Although its existence as an extracellular regulator had been postulated since the late 1950s, it was not until 1989 that MIF was formally identified thanks to cDNA cloning and sequencing (1). A few years later the three dimensional structure of MIF was elucidated by structural analysis of the pure recombinant protein (2-4).

MIF is primarily known as a pro-inflammatory cytokine released by several cell types of the immune system, in particular macrophages and $\mathrm{T}$ cells, although its production is by no way restricted to immune cells. In addition to its paracrine activity, it can also act in endocrine fashion when secreted by corticotrophic cells of the pituitary (5). Physiologically, MIF has been shown to counteract the anti-inflammatory activivity of glucocorticoids at various levels, thus keeping a balance between pro-inflammatory and anti-inflammatory mechanisms (6). Expectedly, a dysregulation/exacerbation of MIF activity has been implicated in pathological conditions as diverse as asthma (7), chronic colitis (8), rheumatoid arthritis (9), systemic lupus erythematosus (10), psoriasis (11) and noninsulin-dependent diabetes mellitus (12).

As also seen for other cytokines such as interleukin-6, evidence is growing that MIF, beside its role in immune responses, could also be involved in neoplastic transformation and tumor progression. Among the earliest experimental observations that MIF might contribute to tumor development was the negative impact of MIF immunoneutralization on neoplastic growth in a mouse model of B cell lymphoma (13).

In the context of human cancer, MIF increase associated with neoplastic diseases was first suggested by ligand histochemistry using sarcolectin (14-16), soon followed by histochemical demonstration of MIF overexpression in prostatic adenocarcinoma metastases (17). More recent studies have reported MIF overexpression in a variety of human 
cancers, such as gastric adenocarcinoma (18), ovarian cancer (19), colorectal carcinoma (20) and cervical cancer (21). In the case of head and neck squamous cell carcinomas (HNSCC), studies by our group have disclosed an enhanced MIF expression in oral cavity, laryngeal and hypopharyngeal squamous cell tumors (22-24). Of particular interest, stable MIF knockdown in a murine ovarian cancer cell line has been shown to decrease tumor burden and confer longer survival in tumor transplanted mice (19). A similar result was obtained after administration of anti-MIF therapeutics, either MIF-neutralizing antibodies or the MIF inhibitor ISO-1, to mice grafted with colorectal carcinoma transplants (20).

MIF exhibits a non-physiologic dopachrome tautomerase activity which has been extensively exploited to screen for potential inhibitors, owing to the fact that compounds antagonizing this enzymatic activity are also likely to disrupt MIF interactions with cognate receptors such as CD74 and suppress thereby its effects on target cells (25). Along this line, a new potent inhibitor of MIF dopachrome tautomerase activity, 4-iodo-6-phenylpyrimidine (4-IPP) has been shown to decrease the motility and anchorage-independent growth of lung adenocarcinoma cells (26).

Since MIF has been reported to be overexpressed in head and neck squamous cell carcinomas (22-24), the present study was undertaken to examine possible inhibitory effects of 4-IPP on SCCVII squamous carcinoma cells.

\section{Materials and methods}

Inhibitor and antibodies. MIF inhibitor 4-iodo-6-phenylpyrimidine (4-IPP) was purchased from Tocris Bioscience (Bristol, UK). Stock solutions of the compound, prepared $\geq 250$-fold concentrated in ethanol, were stored at $-20^{\circ} \mathrm{C}$ and used within the month. Polyclonal antibody against purified MIF (14) was raised in rabbits. Serum IgG fraction was purified as described previously (24). Rabbit polyclonal anti-CD74 antibody (FL-296), raised against residues 17-296 of human CD74, was obtained from Santa Cruz Biotechnology (Santa Cruz, CA). Cell culture medium and supplements were from Lonza (Verviers, Belgium). Fetal bovine serum (FBS) was from Hyclone (Logan, UT). Other chemicals were from standard commercial sources.

Cell line and culture. The squamous cell carcinoma cell line SCCVII (27) was a kind gift from Dr Shulin Li (Louisiana State University). Routine cell propagation and experimental studies were carried out at $37^{\circ} \mathrm{C}$ in a cell incubator with humid atmosphere at $5 \% \mathrm{CO}_{2}$. Unless specified otherwise, cells were cultured in T-flasks containing Dulbecco's modified essential medium (DMEM) supplemented with phenol red, 10\% FBS, $25 \mathrm{mM}$ N-2-hydroxyethylpiperazine-N'-2-ethanesulfonic acid (HEPES), $2 \mathrm{mM}$ L-glutamine and $1 \mathrm{X}$ antibiotic/antimycotic mix.

A CD74 knockdown (CD74-KD) cell line derived from SCCVII, as well as a matched control with normal CD74 expression, were generated in our laboratory. Knockdown of CD74 expression was achieved by using anti-CD74 shRNA (mouse) lentiviral particles from Santa Cruz. Controls were obtained by transduction with shRNA lentiviral particles encoding a scrambled (sc) shRNA sequence (CD74sc). Transduced cells were selected by addition of $4 \mu \mathrm{g} / \mathrm{ml}$ puromycin to the culture medium. Preliminary experiments showed this puromycin concentration to be toxic toward non-transduced SCCVII cells.

Western blotting. Transduced SCCVII cells (CD74sc and CD74KD) were plated in Petri dishes $\left(10^{6}\right.$ cells/dish $)$, cultured for 3 days and then lysed using a detergent cocktail (M-PER Mammalian Extraction buffer) supplemented with protease (Halt Protease Inhibitor Cocktail) and phosphatase inhibitors (Halt Phosphatase Inhibitor Cocktail) (all from Pierce, Rockford, IL, USA). Protein concentrations were determined by the BCA Protein assay (Pierce) using bovine serum albumin as standard. Extracted proteins $(30 \mu \mathrm{g})$ were subjected to $10 \%$ SDS-PAGE and electrotransferred onto nitrocellulose membranes (iBlot ${ }^{\circledR}$ Dry Blotting system, Life Technologies-Invitrogen, Gent, Belgium). Immunodetections were performed using anti-CD74 antibody FL-296 (1/200). Peroxidase-labeled anti-rabbit IgG antibody $(1 / 5,000)$ (from Amersham Pharmacia Biotech, Roosendaal, The Netherlands) was used as secondary reagent. Bound peroxidase activity was revealed using the SuperSignal ${ }^{\circledR}$ West Pico Chemiluminescent Substrate (Pierce) following the manufacturer's instructions. Immunostaining signals were digitalized with a PC-driven LAS-3000 CCD camera (Fujifilm, Tokyo, Japan), using a software specifically designed for image acquisition (Image Reader, Raytest ${ }^{\circledR}$, Straubenhardt, Germany). Immunoreactive band intensities were quantified using the software AIDA $^{\circledR}$ Image Analyser 3.45 (Raytest).

Measurement of cell culture growth by cell counting. SCCVII cells were plated at a density of $10^{4}$ cells $/ \mathrm{cm}^{2}$ in 12 -well dishes. The next day, cell cultures were fed fresh medium with or without 4-IPP (concentrations specified in Results). Measurement of cell culture density was performed either daily (time-course experiment) or after 3 days of treatment. Cells were dislodged from the vessel bottom by treatment with trypsin-EDTA solution (Lonza). After vigorous pipetting, concentrations of cells in suspension were determined in an electronic cell counter (model Z1 Coulter counter, Beckman Coulter, Fullerton CA).

Measurement of cell culture growth by crystal violet stain assay. Cell density was also assessed by colorimetry after crystal violet staining, as described previously (28). Cells were seeded in 96-well plates (1,000-2,000 cells/well). The following day, they were fed fresh medium (DMEM, 10\% FBS) with or without 4-IPP. After a 3-day exposure, the culture medium was discarded and cells were fixed with $1 \%$ glutaraldehyde. Following fixation, cells were stained with $1 \%$ crystal violet. Destaining was achieved under gently running tap water and cell monolayers were lysed in $0.2 \%$ Triton X-100. The absorbance of cell lysates was measured at $570 \mathrm{~nm}$ using a Labsystems Multiskan MS microplate reader.

Measurement of cell culture growth by bromodeoxyuridine incorporation. DNA synthesis in SCCVII cells was evaluated on the basis of bromodeoxyuridine (BrdU) incorporation measured using an enzyme immunoassay kit developed by Roche Diagnostics (Mannheim, Germany). The assay was performed following the manufacturer's instructions, with minor modifications. Briefly, SCCVII cells were plated in 96-well plates (2,000 cells/well) and treated the following 
day with 4-IPP. For the assessment of BrdU incorporation into DNA, the cell cultures were exposed for $50 \mathrm{~min}$ to BrdU labelling solution, followed by fixation and denaturation with an ethanol-based mixture. Thereafter cells were incubated for $30 \mathrm{~min}$ in a blocking solution (Animal-Free Blocker, Vector Laboratories, Burlingame, CA). The next step consisted in incubating cells in the presence of an anti-BrdU antibody conjugated with horseradish peroxidase. Immunocomplexes were detected by using a mixture of $\mathrm{H}_{2} \mathrm{O}_{2}$ /tetramethylbenzidine as substrate. After addition of the stop solution $\left(1 \mathrm{M} \mathrm{H}_{2} \mathrm{SO}_{4}\right)$, the absorbance of the samples was measured at $450 \mathrm{~nm}$ (reference wavelength, $690 \mathrm{~nm}$ ) in a microplate reader.

Cell cycle analysis by flow cytometry. The effect of 4-IPP on SCCVII cell cycle was examined using the Cell Cycle Phase Determination kit from Cayman Chemical Co. (Ann Arbor, MI). Cells were seeded in 6-well plates $(10,000$ cells/well $)$ and cultured for $24 \mathrm{~h}$ prior to exposure to 10,20 or $40 \mu \mathrm{M}$ 4-IPP or vehicle for $48 \mathrm{~h}$. After treatment, cells were collected (trypsin-EDTA solution), centrifuged (500 x g, $5 \mathrm{~min}$ ) and washed twice with assay buffer (Cayman Chemical Co.) before incubation in fixative solution (Cayman Chemical Co.) for at least $2 \mathrm{~h}$. Fixed cells were centrifuged, suspended in $0.5 \mathrm{ml}$ staining solution (propidium iodide and RNase solution) (Cayman Chemical Co.) and incubated for $30 \mathrm{~min}$ at room temperature in the dark. Finally, the samples were analyzed in the FL2 channel of a flow cytometer (FACSCalibur, BectonDickinson, Franklin Lakes, NJ) equipped with a 488-nm excitation laser.

Evaluation of MIF immunoreactivity by enzyme-linked immunosorbent assay. The immunoreactivity of MIF protein was assessed by a sandwich enzyme-linked immunosorbent assay (ELISA) using a commercial kit (DuoSet ELISA Development kit, R\&D Systems, Minneapolis, MN). Ninety-six well ELISA plates were coated overnight with $100 \mu \mathrm{l} /$ well of capture antibody (mouse anti-human MIF). After 3 rinses of the wells with washing buffer (PBS, 0.05\% Tween-20), non-specific binding was prevented by adding the reagent diluent containing $1 \%$ BSA and incubating for $1 \mathrm{~h}$. The above mentioned rinsing procedure was applied between all subsequent steps. The blocking step was followed by the addition of increasing concentrations of human recombinant MIF in reagent diluent. After an incubation period of $2 \mathrm{~h}, 100 \mu \mathrm{l}$ of detection antibody (biotinylated goat anti-human MIF) were added to each well. A 2-h exposure to the detection antibody was followed by a 20-min incubation with $100 \mu 1$ of horseradish peroxidaseconjugated streptavidin. Immunocomplexes were revealed by the addition of $100 \mu \mathrm{l}$ substrate solution $\left(\mathrm{H}_{2} \mathrm{O}_{2} /\right.$ tetramethylbenzidine). After stopping the reaction with $\mathrm{H}_{2} \mathrm{SO}_{4}$, the absorbance of the samples was measured at $450 \mathrm{~nm}$ (reference wavelength, $570 \mathrm{~nm}$ ) as described above.

Immunofluorescence microscopy. SCCVII cells were plated at a density of 5,000 cells $/ \mathrm{cm}^{2}$ on sterile round glass coverslips in 12-well dishes. The following day, they were fed fresh medium with or without $20 \mu \mathrm{M}$ 4-IPP. After 3 days of drug exposure, cell monolayers were fixed with $4 \%$ paraformaldehyde in Dulbecco's PBS (DPBS). Following fixation, paraformaldehyde was changed for DPBS where cell cultures were stored at $4^{\circ} \mathrm{C}$ until immunostaining. Before application of antibodies, cell monolayers were rinsed several times with PBS $(0.04 \mathrm{M}$ $\mathrm{Na}_{2} \mathrm{HPO}_{4}, 0.01 \mathrm{M} \mathrm{KH}_{2} \mathrm{PO}_{4}, 0.12 \mathrm{M} \mathrm{NaCl}, \mathrm{pH}$ 7.2) containing $0.1 \%$ Triton $\mathrm{X}-100$ (the same detergent-containing buffer was used for subsequent incubations and rinsing steps). Prior to exposure to primary antibodies, cells were preincubated for 20 min in PBS containing $0.05 \%$ casein and $0.05 \mathrm{M} \mathrm{NH}_{4} \mathrm{Cl}$ to prevent non-specific adsorption of immunoglobulins. Cells were exposed for $60 \mathrm{~min}$ to the primary antibody (either anti-MIF or anti-CD74) diluted 1:50 in PBS containing 0.05\% casein. This was followed by a 30-min exposure to biotinylated goat anti-rabbit IgG (Vector Laboratories). Thereafter, the cell preparations were incubated for $30 \mathrm{~min}$ in the presence of Texas Red-conjugated streptavidin (Vector Laboratories). After final rinses in PBS, the coverslips were mounted on glass slides using commercial anti-fading medium (Vectashield ${ }^{\circledR}$, Vector Laboratories). Negative controls were produced by omitting the incubation step with primary antibodies. This modification resulted in a decrease of the fluorescence signal to background level.

The cell preparations were examined on a Leitz Orthoplan microscope equipped with a Ploem system for epi-illumination. Excitation wavelength of $560 \mathrm{~nm}$ and emission wavelength of $590 \mathrm{~nm}$ were used for the observation of Texas Red fluorescence. Image capture was achieved using a PC-driven digital camera (Leica DC 300F, Leica Microsystems AG, Heerbrugg, Switzerland) operated with Leica IM50 software. Quantitative analysis of fluorescence signals was performed on digitalized images thanks to Image $\mathrm{J}^{\mathrm{TM}}$ (a public domain image software developed by W. Rasband at the Research Services Branch of the National Institute of Mental Health, NIH). Images were analyzed in the red channel after RGB split. Gray levels (on a scale of 0-225), corresponding to fluorescence intensity were determined in 65 cells in each control or treated cultures. Distribution histograms were plotted using Sigma Plot (Systat Software, Inc., Hounslow, UK). Confocal microscopy observations were carried out using an Olympus FV1000D laser scanning inverted microscope equipped with a red laser diode (LD559).

Phase contrast microscopy. Appearance of live cells in cultures was documented by phase-contrast microscopy using a Wilovert inverted microscope (Leitz, Wetzlar, Germany) equipped with a Leica DC 300F digital camera (see above).

Cell migration assay. Cell invasiveness was assessed by a Boyden chamber assay consisting of 24-well plates (lower chambers) with cell culture inserts (upper chambers), both chambers being separated by a polycarbonate membrane (8- $\mu \mathrm{m}$ size) coated with an artificial extracellular matrix (Chemicon Cell Invasion Assay kit, Millipore, Billerica, MA). The kit was used according to the manufacturer's instructions. SCCVII cells were seeded in cell culture inserts $\left(1.5 \times 10^{5}\right.$ cells/insert) in serum-free medium (DMEM). The lower chambers were filled with complete medium (DMEM, $10 \%$ FBS) with or without $40 \mu \mathrm{M} 4$-IPP $(\mathrm{n}=4)$. After $96 \mathrm{~h}$, cells were wiped off the upper surface of cell culture inserts with a cotton-tipped swab and the migrating cells were stained with crystal violet and counted in 6 microscopic fields (magnification x10) using a Zeiss Axio scope A1 microscope (Carl Zeiss, Germany). 

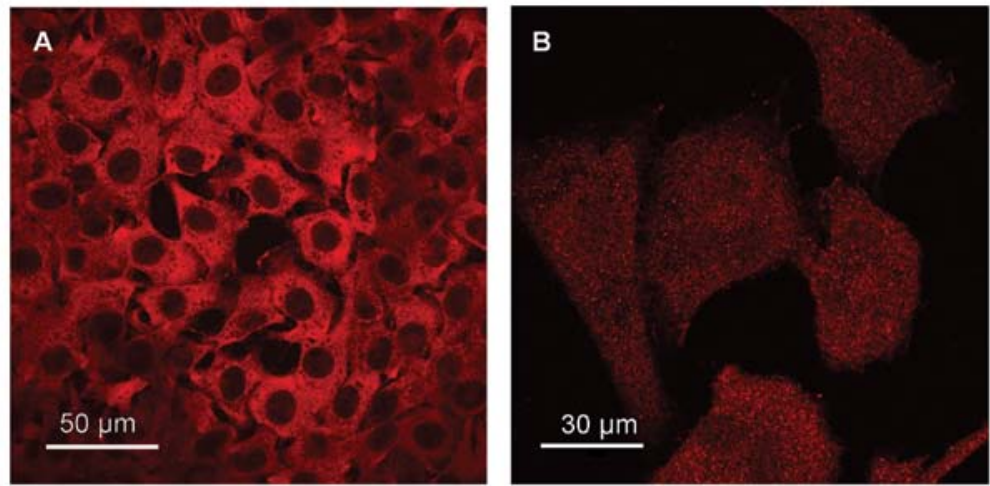

Figure 1. Demonstration of MIF (A) and CD74 (B) in SCCVII cells by immunofluorescence microscopy. Texas Red labelling, confocal microscopy.
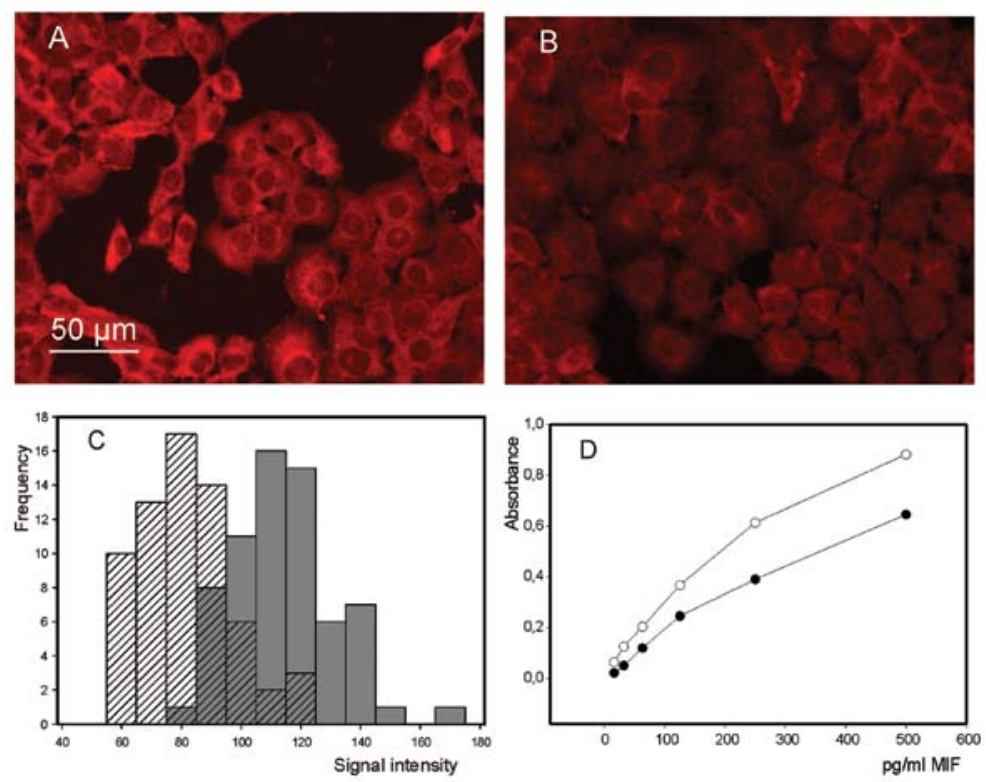

Figure 2. Alteration of MIF immunoreactivity by 4-IPP. (A and B) Intensity of MIF immunofluorescence signal in untreated cells (A) and cells treated for 3 days with 4-IPP $(20 \mu \mathrm{M})$ (B). (C) Distribution histogram of fluorescence intensities for untreated cells (grey bars) and treated cells (hatched bars). (D) MIF immunoreactivity assessed by ELISA (duplicate measurements) after a 24-h exposure to 4-IPP ( $40 \mu \mathrm{M})$ (filled symbols). Open symbols, human recombinant MIF assayed in parallel in absence of 4-IPP.

Statistical analyses. SigmaPlot ${ }^{\circledR} 11$ software was used for statistical analyses. Parametric analysis was performed by ANOVA ( $>2$ groups, pairwise comparisons achieved by the Holm-Sidak method) or Student's t-test (2 groups). Non-parametric analysis used the Mann-Whitney rank sum test.

\section{Results}

SCCVII cells express both MIF and CD74. Demonstration of MIF in SCCVII cells by immunofluorescence microscopy is illustrated in Fig. 1A. MIF immunoreactivity is extranuclear and appears distributed throughout the cytoplasm of cells. Unlike that recently reported for MIF distribution in glioblastoma cells (29), the current data give no evidence of a prominent perinuclear localization. Similar to MIF, CD74 seems to be expressed by most, if not all SCCVII cells. Immunoreactive CD74 exhibits a punctuated pattern on the whole cell surface (Fig. 1B), a distribution consistent with the membrane localization of the receptor.
4-IPP alters MIF immunoreactivity. Fluorescence microscopy examination of MIF in 4-IPP-treated cells revealed a decrease in the intensity of immunofluorescence signal (Fig. 2A and B), further confirmed by image analysis (Fig. 2C). Even though this observation is suggestive of a decrease in MIF expression, the inhibitory action of 4-IPP should not be expected to affect cell MIF content. Yet, it is well known that 4-IPP, like other irreversible MIF inhibitors, reacts covalently with the N-terminal proline of MIF (26), inducing thereby a conformational change of the protein that could modify its immunoreactivity. Thus, we checked MIF immunoreactivity by enzyme-linked immunoassay in presence and absence of 4-IPP. As revealed by data presented in Fig. 2D, the addition of 4-IPP resulted in a marked decrease of absorbance associated with the formation of immunocomplexes, clearly showing that 4-IPP drastically alters MIF immunoreactivity.

4-IPP inhibits the proliferation of SCCVII cells. Routine examination of SCCVII cell cultures exposed to 4-IPP 

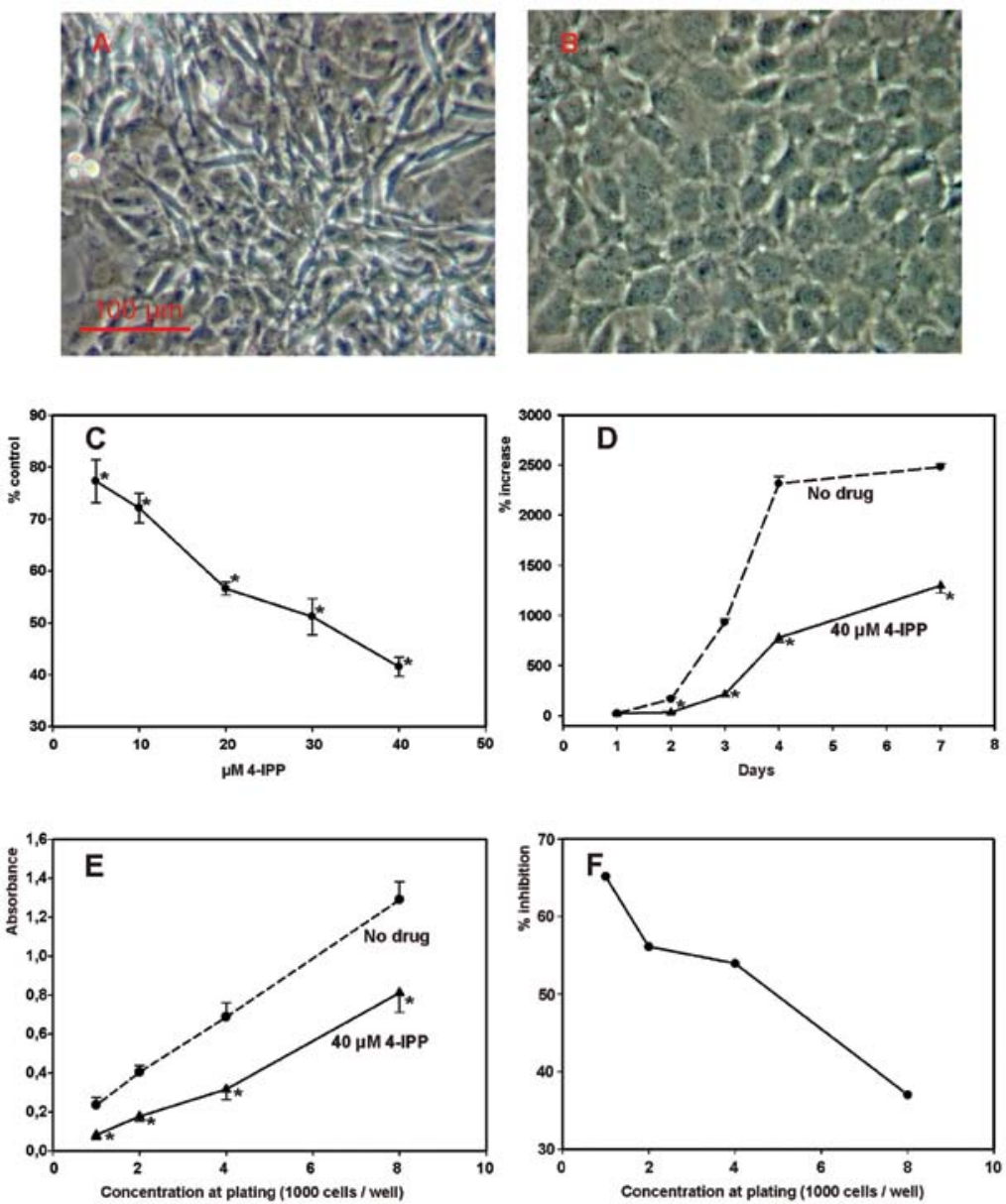

Figure 3. Effect of 4-IPP on SCCVII cell proliferation. (A and B) Appearance of cell cultures 7 days after plating. (A) No drug. (B) Cells grown in presence of $40 \mu \mathrm{M}$ 4-IPP (6 days). (C) Dose-effect relationship (cells counted after a 3-day exposure to 4-IPP, each symbol is the mean of 4 determinations \pm SD) (ANOVA, differences versus control assessed by Holm-Sidak method, $\left.{ }^{*} \mathrm{p}<0.001\right)$. (D) Time-course of cell culture growth (\% increase in cell number determined by cell counting, each symbol is the mean of 4 determinations \pm SD) (differences versus controls assessed by Student's t-test, " $p<0.001$ ). (E and F) Inhibition of cell culture growth, as assayed by crystal violet staining. (E) Absorbance relative to cell concentration at plating (each symbol is the mean of 6 determinations \pm SD) (differences versus controls assessed by Student's t-test, $\left.{ }^{*} \mathrm{p}<0.001\right)$. (F) Percent inhibition as a function of cell concentration at plating, calculated from data (E).
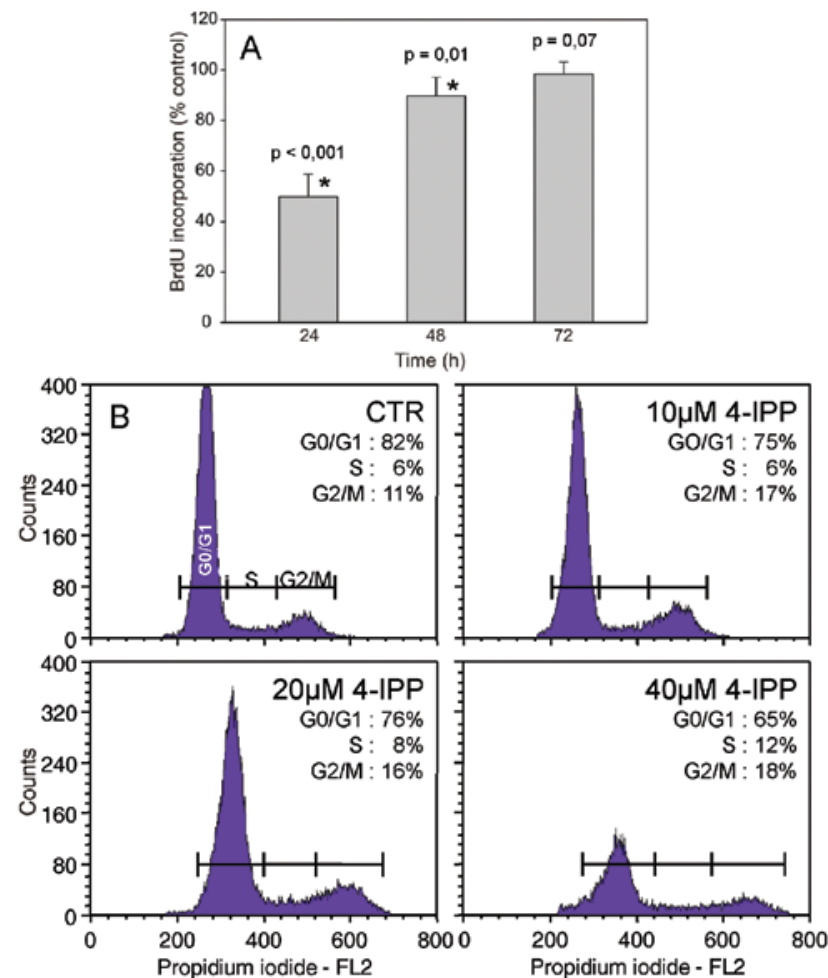

(Fig. 3A and B) suggested that the MIF inhibitor might exert an inhibitory effect on cell proliferation. Thus, cell culture growth studies were conducted in order to disclose a possible effect of MIF inhibition on cell proliferation. As illustrated in Fig. 3C, 4-IPP provoked a dose-dependent decrease of cell culture growth with an $\mathrm{IC}_{50} \sim 30 \mu \mathrm{M}$. At $40 \mu \mathrm{M}$ 4-IPP, its inhibitory action on cell proliferation was already apparent after 1 day of exposure (Fig. 3D). Observations based on cell counting were confirmed by crystal violet stain assay (Fig. 3E). In the latter assay, the extent of the cytostatic effect produced by 4-IPP was inversely related to cell plating concentration (Fig. 3F). IPP-4-induced decline in cell proliferation prompted us to examine the effect of the MIF inhibitor on DNA synthesis and the cell division cycle. Cell treatment with 4-IPP resulted in a transient reduction of BrdU incorporation into DNA, which lasted 2 days after drug addition (Fig. 4A). As shown by flow

Figure 4. Effect of 4-IPP on DNA synthesis and the cell cycle. (A) Inhibition of BrdU incorporation into DNA by 4-IPP $(40 \mu \mathrm{M})$ as function of the duration of drug exposure (each symbol is the mean of 6 determinations $\pm \mathrm{SD}$ ) (data analysis by Student's t-test). (B) Impact of 4-IPP on SCCVII cell cycle. Flow cytometry analysis performed after 2 days of drug exposure. 


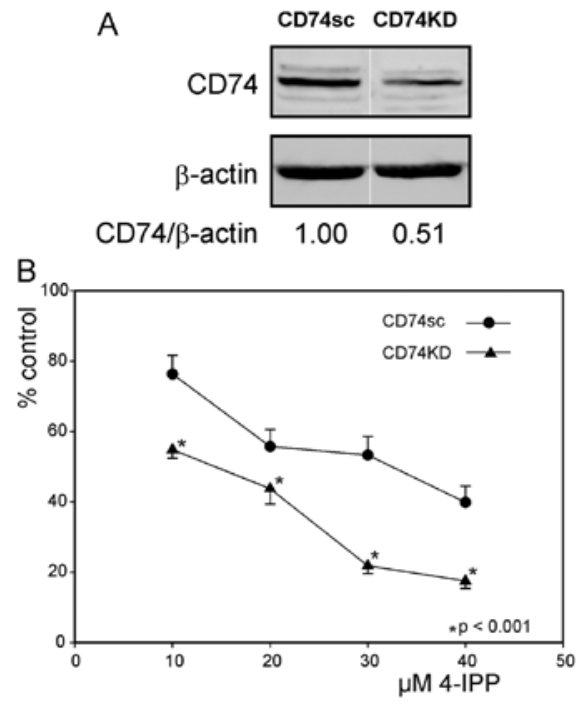

Figure 5. (A) Demonstration by western blotting of CD74 reduction obtained by shRNA transduction in SCCVII cells. (B) Dose-dependent inhibition of cell culture growth in SCCVII with CD74 knockdown (CD74KD) as compared to control transduced cells (CD74sc). Cells were plated at a density of 1,000 cells/well and exposed to 4-IPP one day after seeding. Cell cultures were processed for crystal violet staining after 3 days of drug exposure. In absence of 4-IPP treatment, CD74KD cell growth was reduced by $31 \%$ relative to $C D 74 \mathrm{sc}$ cell growth $(\mathrm{p}<0.001)$. Data are expressed relative to untreated CD74KD or CD74sc cells. Statistical analysis of differences between CD74KD and CD74sc cells was performed by Student's t-test.

cytometry analysis of the cell cycle, a 2-day exposure to 4-IPP led to a substantial cell accumulation in the G2/M phase of the cell cycle.
Expression of CD74 modulates SCCVII cell sensitivity to 4-IPP. MIF action on target cells notably depends on binding of its cognate receptor CD74 and the ensuing activation of downstream transduction cascade(s). Thus, we wondered whether a change of CD74 expression in SCCVII might influence their sensitivity to 4-IPP. The expression of CD74 was partially abrogated by lentiviral transduction of shRNA targeting the transcript (Fig. 5A). Fig. 5B illustrates the inhibition of growth induced by 4-IPP in CD74KD cells, as compared to control CD74sc cells. Blunting of CD74 expression clearly sensitizes cells to the cytostatic action of 4-IPP.

4-IPP reduces cell invasiveness. To evaluate whether MIF activity correlates with the invasiveness of SCCVII cells, we performed an in vitro cell invasion assay to determine the effect of 4-IPP on cell migration in Boyden chambers. 4-IPP at a concentration of $40 \mu \mathrm{M}$ reduced the number of cells that migrated through the membrane as compared to untreated cells (Fig. 6A). The decrease of cell migration as a result of 4-IPP action was quantified by cell counting (Fig. 6B, p=0.005). This result suggests that MIF promotes cell migration through extracellular matrix and could contribute to tumor invasiveness in vivo.

\section{Discussion}

The prominent role of MIF as a proinflammatory cytokine makes it an attractive therapeutic target for the management of autoinflammatory disorders. Thus, there has been an intensive search for pharmacological compounds capable of blocking MIF activity. The design of new molecules and the high throughput screening for potential MIF inhibitors have

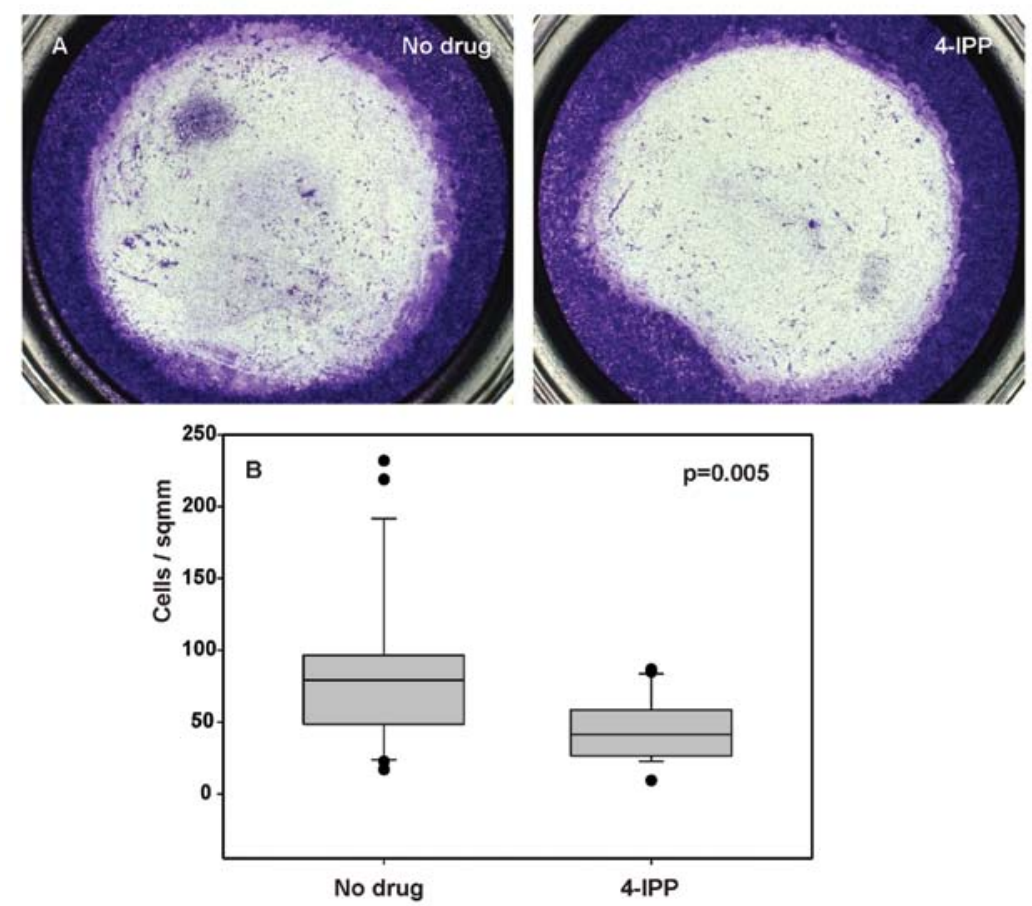

Figure 6. Influence of 4-IPP on the migration capacities of SCCVII cells. Inserts of Boyden chambers were seeded with SCCVII cells (1.5x105 cells per insert, four inserts per group). Membranes were stained $96 \mathrm{~h}$ after seeding and cells were removed from upper surface of the membranes by wiping with a moist cotton swab. (A) Typical fields showing the lower surface of inserts in absence or presence on 4 -IPP (40 $\mu \mathrm{M}$ added to the lower chamber). (B) Cell densities on the lower surface, as determined by cell counting (see Materials and methods for details). Statistical analysis by Mann-Whitney test ( $\mathrm{n}=23 \mathrm{measurements)}$. 
been facilitated by the fact that MIF possesses an enzymatic activity of D-dopachrome tautomerase. Albeit of unknown physiological significance, this tautomerase activity has been exploited as a validation tool for the identification of MIF inhibitors, since substances blocking this enzymatic activity would also be likely to interfere with MIF binding to its cognate receptor CD74. The first published report of a pharmacologically active MIF inhibitor described the properties of ISO-1 ((S,R)-3-(4-hydroxyphenyl)-4,5-dihydro-5-isoxazole acetic acid methyl ester). In vitro, ISO-1 was shown to abrogate MIF-mediated macrophage response to bacterial endotoxin, whereas in vivo it improved animal survival in a murine model of peritonitis-induced sepsis (30).

There is converging evidence that MIF contributes to tumor progression in various human cancers. In particular, recent observations of our group suggest an involvement of MIF in HNSCC. Indeed, immunohistochemistry reveals an increase of MIF immunostaining intensity during progression to neoplasia in hypopharyngeal (24), oral cavity (22) and laryngeal (23) squamous cell carcinomas. Higher serum levels were also found in patients with HNSCC, as compared to healthy individuals (23). These clinical observations were complemented by in vitro and in vivo studies on squamous cell carcinoma cell line SCCVII, where we showed that MIF knockdown decreases cell proliferation and motility and increases cell sensitivity to the anticancer drugs cisplatin and 5-fluorouracil (23).

Insofar as MIF seems to contribute to tumor progression, MIF inhibitors might be effective as anticancer drugs. Lending support to this assertion, ISO-1 has been reported to reduce the proliferation of glioblastoma multiforme cells in vitro (29) and inhibit the growth of tumor xenografts produced by the inoculation of prostate cancer cells (31) or colon carcinoma cells (20). In the present study, we investigated the impact of pharmacological MIF inhibition on the behaviour of SCCVII squamous carcinoma cells, since previous observations show that they are partially dependent on endogenous MIF for growth (23). As a test compound, we used 4-IPP (4-iodo6-phenylpyrimidine), a suicide substrate which has been recently shown to exhibit 5-10 times more inhibitory potency than ISO-1 (26).

In the present study, preliminary experiments based on immunofluorescence staining revealed that SCCVII cells exhibit both MIF and CD74 immunoreactivities. Although similar studies have rarely been performed on tumor cells, MIF and CD74 have been previously shown to be co-expressed in non-small cell lung cancer (32). The intracellular pattern of MIF immunofluorescence in SCCVII cells was reminiscent of that reported for macrophages (33). As could be expected for a cell surface receptor, the distribution of immunoreactive CD74 markedly differed from that of MIF. Assuming that MIF can be secreted by SCCVII cells, the simultaneous expression of the cytokine and its receptor implies the possibility of autocrine stimulation.

The finding that 4-IPP treatment resulted in a decrease of MIF immunofluorescence intensity in SCCVII cells was at first sightly surprising since MIF inhibition has not been reported to decrease the expression of the cytokine in treated cells. As a matter of fact, ISO-1 has been observed to enhance rather than reduce MIF expression in glioblastoma multiforme cells (29).
Further investigations relying on ELISA showed that 4-IPP actually alters MIF immunoreactivity, a finding consistent with a covalent modification of the latter. Similar observations on 4-IPP-induced alteration of MIF immunoreactivity have been reported previously (33).

Assessment of cell proliferation in presence of 4-IPP showed that the drug exerts a dose-dependent cytostatic effect on SCCVII cells, without evidence of apoptotic cells in treated cultures. CD74 knock-down definitely resulted in an increase of SCCVII cell sensitivity to 4-IPP. The additive effect of CD74 knock-down and 4-IPP suggests that MIF promotes SCCVII cell proliferation by interacting with CD74/CD44 and triggering downstream signalling events. Although the identity of the signalling pathway was not specifically investigated in the present study, MIF-induced enhancement of cell proliferation is generally assumed to occur via the activation of the ERK1/2 transduction cascade and the ensuing expression cell cycle proteins required for progression through $\mathrm{G} 1 / \mathrm{S}$ $(34,35)$. As shown recently with renal carcinoma cell lines, MIF also promotes cell proliferation by activating Src, which in turn phosphorylates and destabilizes cdk inhibitor $\mathrm{p} 27^{\mathrm{Kip} 1}$ (36). Insofar as MIF contributes to cell progression through G1/S phase, its inhibition would be expected to result in cell accumulation in G0/G1 phase. Such arrest in G0/G1 has indeed been demonstrated in HEK293 cells after MIF knockdown (37). Yet, cell cycle analysis by flow cytometry revealed that 4-IPP-treated SCCVII cells accumulate in G2/M. This observation raises the intriguing possibility that MIF might be involved in the control of mitosis by acting on $\mathrm{G} 2 / \mathrm{M}$ regulators such as cde 25 .

In the original report describing 4-IPP as a newly designed MIF inhibitor, the latter was shown to abrogate the migration of A549 lung carcinoma cells through collagen-coated membranes. Using a similar assay system, we noted that 4-IPP interferes with SCCVII cell migration across ECM-coated membranes. In a variety of neoplasms, MIF expression has been shown to correlate with tumor invasiveness/aggressivity. The mechanisms underlying MIF effects on tumor cell motility/invasiveness still remain a matter of debate and might depend on cell context. Observations on A549 cells point to involvement of the Rho GTPase Racl as an effector mediating MIF action on cell migration/invasiveness (38). A more recent study on chondrosarcoma cells suggests that MIF enhances cell migration via activation of the $\mathrm{PI} 3 \mathrm{~K} / \mathrm{Akt} / \mathrm{NF} \kappa \mathrm{B}$ signal transduction pathway and an increase of $\alpha v \beta 3$ integrin expression (39).

The present study showed that pharmacological inhibition of MIF in squamous carcinoma cells resulted in impaired proliferation and invasiveness. HNSCC is not only a life-threatening disease, but its treatment can also be particularly debilitating. As revealed by a recent study of our group (23), MIF expression in HNSCC correlates with an unfavourable prognosis. Thus, the use of MIF inhibitors, particularly in conjunction with CD74 inhibition, might open new opportunities for target-directed treatment of these neoplasms.

\section{Acknowledgements}

N.K. is the recipient of a fellowship from the Fondation Rose and Jean Hoguet. G.L. is Senior Research Associate 
of the National Fund for Scientific Research (Belgium) and the recipient of a grant from the Belgian Fund for Medical Scientific Research.

\section{References}

1. Weiser WY, Temple PA, Witek-Giannotti JS, Remold HG, Clark SC and David JR: Molecular cloning of a cDNA encoding a human macrophage migration inhibitory factor. Proc Natl Acad Sci USA 86: 7522-7526, 1989.

2. Sugimoto H, Suzuki M, Nakagawa A, Tanaka I and Nishihira J: Crystal structure of macrophage migration inhibitory factor from human lymphocyte at 2.1 A resolution. FEBS Lett 389: 145-148, 1996.

3. Sun HW, Bernhagen J, Bucala R and Lolis E: Crystal structure at 2.6-A resolution of human macrophage migration inhibitory factor. Proc Natl Acad Sci USA 93: 5191-5196, 1996.

4. Kato Y, Muto T, Tomura T, Tsumura H, Watarai H, Mikayama T, Ishizaka $\mathrm{K}$ and Kuroki R: The crystal structure of human glycosylation-inhibiting factor is a trimeric barrel with three 6-stranded beta-sheets. Proc Natl Acad Sci USA 93: 3007-3010, 1996.

5. Nishino T, Bernhagen J, Shiiki H, Calandra T, Dohi K and Bucala R: Localization of macrophage migration inhibitory factor (MIF) to secretory granules within the corticotrophic and thyrotrophic cells of the pituitary gland. Mol Med 1: 781-788, 1995.

6. Flaster H, Bernhagen J, Calandra T and Bucala R: The macrophage migration inhibitory factor-glucocorticoid dyad: regulation of inflammation and immunity. Mol Endocrinol 21: 1267-1280, 2007.

7. Rossi AG, Haslett C, Hirani N, Greening AP, Rahman I, Metz CN, Bucala R and Donnelly SC: Human circulating eosinophils secrete macrophage migration inhibitory factor (MIF). Potential role in asthma. J Clin Invest 101: 2869-2874, 1998

8. de Jong YP, Abadia-Molina AC, Satoskar AR, Clarke K. Rietdijk ST, Faubion WA, Mizoguchi E, Metz CN, Alsahli M, ten Hove T, Keates AC, Lubetsky JB, Farrell RJ, Michetti P, van Deventer SJ, Lolis E, David JR, Bhan AK and Terhorst C: Development of chronic colitis is dependent on the cytokine MIF. Nat Immunol 2: 1061-1066, 2001.

9. Morand EF, Leech M, Weedon H, Metz C, Bucala R and Smith MD: Macrophage migration inhibitory factor in rheumatoid arthritis: clinical correlations. Rheumatology (Oxford) 41: 558-562, 2002

10. Foote A, Briganti EM, Kipen Y, Santos L, Leech M and Morand EF: Macrophage migration inhibitory factor in systemic lupus erythematosus. J Rheumatol 31: 268-273, 2004.

11. Donn RP, Plant D, Jury F, Richards HL, Worthington J, Ray DW and Griffiths CE: Macrophage migration inhibitory factor gene polymorphism is associated with psoriasis. J Invest Dermatol 123: 484-487, 2004.

12. Sanchez-Zamora Y, Terrazas LI, Vilches-Flores A, Leal E, Juárez I, Whitacre C, Kithcart A, Pruitt J, Sielecki T, Satoskar AR and Rodriguez-Sosa M: Macrophage migration inhibitory factor is a therapeutic target in treatment of non-insulin-dependent diabetes mellitus. FASEB J 24: 2583-2590, 2010.

13. Chesney J, Metz C, Bacher M, Peng T, Meinhardt A and Bucala R: An essential role for macrophage migration inhibitory factor (MIF) in angiogenesis and the growth of a murine lymphoma. Mol Med 5: 181-191, 1999.

14. Zeng F-Y, Weiser WY, Kratzin H, Stahl B, Karas M and Gabius HJ: The major binding protein of the interferon antagonist sarcolectin in human placenta is a macrophage migration inhibitory factor? Arch Biochem Biophys 303: 74-80, 1993.

15. Zeng FY, Gerke V and Gabius HJ: Characterization of the macrophage migration inhibitory factor-binding site of sarcolectin and its relationship to human serum albumin. Biochem Biophys Res Commun 200: 89-94, 1994.

16. Kayser K, Bovin NV, Korchagina EY, Zeilinger C, Zeng FY and Gabius H-J: Correlation of expression of binding sites for synthetic blood group A-, B- and H-trisaccharides and for sarcolectin with survival of patients with bronchial carcinoma. Eur J Cancer 30A: 653-657, 1994.

17. Meyer-Siegler K and Hudson PB: Enhanced expression of macrophage migration inhibitory factor in prostatic adenocarcinoma metastases. Urology 48: 448-452, 1996.
18. He XX, Yang J, Ding YW, Liu W, Shen QY and Xia HH: Increased epithelial and serum expression of macrophage migration inhibitory factor (MIF) in gastric cancer: potential role of MIF in gastric carcinogenesis. Gut 55: 797-802, 2006.

19. Hagemann T, Robinson SC, Thompson RG, Charles K, Kulbe H and Balkwill FR: Ovarian cancer cell-derived migration inhibitory factor enhances tumor growth, progression, and angiogenesis. Mol Cell Ther 6: 1993-2002, 2007.

20. He XX, Chen K, Yang J, Li XY, Gan HY, Liu CY, Coleman TR and Al-Abed Y: Macrophage migration inhibitory factor promotes colorectal cancer. Mol Med 15: 1-10, 2009.

21. Krockenberger M, Engel JB, Kolb J, Dombrowsky Y, Häusler SF, Kohrenhagen N, Dietl J, Wischhusen J and Honig A: Macrophage migration inhibitory factor expression in cervical cancer. J Cancer Res Clin Oncol 136: 651-657, 2010.

22. Kindt N, Lechien J, Decaestecker C, Rodriguez A, Chantrain G, Remmelink M, Laurent G, Gabius H-J and Saussez S: Expression of macrophage migration-inhibitory factor is correlated with progression in oral cavity carcinomas. Anticancer Res 32: 4499-4505, 2012.

23. Kindt N, Preillon J, Kaltner H, Gabius H-J, Chevalier D, Rodriguez A, Johnson BD, Megalizzi V, Decaestecker C, Laurent G and Saussez S: Macrophage migration inhibitory factor in head and neck squamous cell carcinoma: clinical and experimental studies. J Cancer Res Clin Oncol 139: 727-737, 2013.

24. Cludts S, Decaestecker C, Johnson B, Lechien J, Leroy X, Kindt N, Kaltner H, André S, Gabius HJ and Saussez S: Increased expression of macrophage migration inhibitory factor during progression to hypopharyngeal squamous cell carcinoma. Anticancer Res 30: 3313-3319, 2010.

25. Cournia Z, Leng L, Gandavadi S, Du X, Bucala R and Jorgensen WL: Discovery of human macrophage migration inhibitory factor (MIF)-CD74 antagonists via virtual screening. J Med Chem 52: 416-424, 2009.

26. Winner M, Meier J, Zierow S, Rendon BE, Crichlow GV, Riggs R, Bucala R, Leng L, Smith N, Lolis E, Trent JO and Mitchell RA: A novel, macrophage migration inhibitory factor suicide substrate inhibits motility and growth of lung cancer cells. Cancer Res 68: 7253-7257, 2008

27. Khurana D, Martin EA, Kasperbauer JL, O'Malley BW Jr, Salomao DR, Chen L and Strome SE: Characterization of a spontaneously arising murine squamous cell carcinoma (SCC VII) as a prerequisite for head and neck cancer immunotherapy. Head Neck 23: 899-906, 2001.

28. Journe F, Chaboteaux C, Dumon JC, Leclercq G, Laurent G and Body JJ: Steroid-free medium discloses oestrogenic effects of the bisphosphonate clodronate on breast cancer cells. Br J Cancer 91: 1703-1710, 2004

29. Baron N, Deuster O, Noelker C, Stüer C, Strik H, Schaller C, Dodel R, Meyer B and Bacher M: Role of macrophage migration inhibitory factor in primary glioblastoma multiforme cells. J Neurosci Res 89: 711-717, 2011.

30. Al-Abed Y, Dabideen D, Aljabari B, Valster A, Messmer D, Ochani M, Tanovic M, Ochani K, Bacher M, Nicoletti F, Metz C, Pavlov VA, Miller EJ and Tracey KJ: ISO-1 binding to the tautomerase active site of MIF inhibits its pro-inflammatory activity and increases survival in severe sepsis. J Biol Chem 280: 36541-36544, 2005.

31. Meyer-Siegler KL, Iczkowski KA, Leng L, Bucala R and Vera PL: Inhibition of macrophage migration inhibitory factor or its receptor (CD74) attenuates growth and invasion of DU-145 prostate cancer cells. J Immunol 177: 8730-8739, 2006.

32. McClelland M, Zhao L, Carskadon S and Arenberg D: Expression of CD74, the receptor for macrophage migration inhibitory factor, in non-small cell lung cancer. Am J Pathol 174: 638-646, 2009.

33. Merk M, Baugh J, Zierow S, Leng L, Pal U, Lee SJ, Ebert AD, Mizue Y, Trent JO, Mitchell R, Nickel W, Kavathas PB, Bernhagen $\mathrm{J}$ and Bucala R: The Golgi-associated protein p115 mediates the secretion of macrophage migration inhibitory factor. J Immunol 182: 6896-6906, 2009.

34. Lue H, Kapurniotu A, Fingerle-Rowson G, Roger T, Leng L, Thiele M, Calandra T, Bucala R and Bernhagen J: Rapid and transient activation of the ERK MAPK signalling pathway by macrophage migration inhibitory factor (MIF) and dependence on JAB1/CSN5 and Src kinase activity. Cell Signal 18: 688-703, 2006.

35. Bifulco C, McDaniel K, Leng L and Bucala R: Tumor growthpromoting properties of macrophage migration inhibitory factor. Curr Pharm Des 14: 3790-3801, 2008. 
36. Du W, Wright BM, Li X, Finke J, Rini BI, Zhou M, He H, Lal P and Welford SM: Tumor-derived macrophage migration inhibitory factor promotes an autocrine loop that enhances renal cell carcinoma. Oncogene 32: 1469-1474, 2013.

37. Liu L, Ji C, Chen J, Li Y, Fu X, Xie Y, Gu S and Mao Y: A global genomic view of MIF knockdown-mediated cell cycle arrest. Cell Cycle 7: 1678-1692, 2008.

38. Rendon BE, Roger T, Teneng I, Zhao M, Al-Abed Y, Calandra T and Mitchell RA: Regulation of human lung adenocarcinoma cell migration and invasion by macrophage migration inhibitory factor. J Biol Chem 282: 29910-29918, 2007.
39. Lee CY, Su MJ, Huang CY, Chen MY, Hsu HC, Lin CY and Tang CH: Macrophage migration inhibitory factor increases cell motility and up-regulates $\alpha v \beta 3$ integrin in human chondrosarcoma cells. J Cell Biochem 113: 1590-1598, 2012. 